\title{
Efficacy and safety of decitabine in treatment of elderly patients with acute myeloid leukemia: A systematic review and meta- analysis
}

\author{
Pin-Fang $\mathrm{He}^{1,2, *}$, Jing-Dong Zhou ${ }^{4, *}$, Dong-Ming $\mathrm{Yao}^{3, *}$, Ji-Chun Ma ${ }^{1,2}$, Xiang-Mei \\ Wen $^{1,2}$, Zhi-Hui Zhang ${ }^{4}$, Xin-Yue Lian ${ }^{4}$, Zi-Jun $X u^{1,2}$, Jun Qian ${ }^{4}$ and Jiang Lin ${ }^{1,2}$ \\ ${ }^{1}$ Laboratory Center, Affiliated People's Hospital of Jiangsu University, Zhenjiang 212002, Jiangsu, P.R. China \\ ${ }^{2}$ The Key Lab of Precision Diagnosis and Treatment of Zhenjiang City, Zhenjiang 212002, Jiangsu, P.R. China \\ ${ }^{3}$ Department of Clinical Laboratory, Affiliated People's Hospital of Jiangsu University, Zhenjiang 212002, Jiangsu, P.R. China \\ ${ }^{4}$ Department of Hematology, Affiliated People's Hospital of Jiangsu University, Zhenjiang 212002, Jiangsu, P.R. China \\ *These authors contributed equally to this work
}

Correspondence to: Jiang Lin, email: linjiangmail@sina.com

Jun Qian, email: qianjun0007@hotmail.com

Keywords: acute myeloid leukemia ( $A M L)$, decitabine, elderly patient, systematic review, meta-analysis

Received: December 08, $2016 \quad$ Accepted: April 11, $2017 \quad$ Published: April 19, 2017

Copyright: He et al. This is an open-access article distributed under the terms of the Creative Commons Attribution License 3.0 (CC BY 3.0), which permits unrestricted use, distribution, and reproduction in any medium, provided the original author and source are credited.

\section{ABSTRACT}

Elderly patients with acute myeloid leukemia (AML) have limited treatment options concerned about their overall fitness and potential treatment related mortality. Although a number of clinical trials demonstrated benefits of decitabine treatment in elderly AML patients, the results remains controversial. A meta-analysis was performed to evaluate efficacy and safety of decitabine in treatment of elderly AML patients. Eligible studies were identified from PubMed, Web of Science, Embase and Cochrane Library. Nine published studies were included in the meta-analysis, enrolling 718 elderly AML patients. The efficacy outcomes were complete remission (CR), overall response rate (ORR) and overall survival (OS). Safety was evaluated based on treatment related grades 3-4 adverse events (AEs) and early death (ED) rate. Pooled estimates with $95 \%$ confidence interval (CI) for CR, ORR and OS were $27 \%(95 \%$ CI 19\%-36\%), 37\% (95\% CI 28\%-47\%) and 8.09 months (95\% CI 5.77-10.41), respectively. The estimated treatment related early death (ED) incidences were within 30 -days $7 \%$ (95\% CI 2\%-11\%) and 60-days 17\% (95\% CI 11\%-22\%), respectively. Thrombocytopenia was the most common grades 3-4 AEs. Subgroup analyses of age, cytogenetics risk, AML type and bone marrow blast percentage showed no significant differences of treatment response to decitabine. In conclusion, decitabine is an effective and well-tolerated therapeutic alternative with acceptable side effects in elderly AML patients.

\section{INTRODUCTION}

Acute myeloid leukemia (AML) is a heterogeneous malignant disease, characterized by clonal abnormal proliferation of hematopoietic stem or progenitor cells, causing marrow failure and death within months or even weeks if diagnosis and treatment time is delayed [1]. The incidence of AML increases progressively with age, and advanced age is an adverse prognostic factor in AML patients $[2,3]$. Poor prognosis of elderly AML patients is due to several different factors, including comorbid conditions, decreased organ function, poor performance status and a higher incidence of adverse karyotypes $[4,5]$. Although intensive chemotherapy can bring a high rate of complete remission (CR) in elderly AML patients, the probable toxicity and fatal side effects limit the extensive application in elderly patients unfit for intensive therapy [6].

Decitabine (5-aza-2'-deoxycytidine, dacogen), a hypomethylating agent, is a deoxynucleoside analogue of cytidine which has hypomethylating effect on DNA at low-dose. Hypomethylating agents, demethylating the promoters of tumor suppressor genes and reactivating their 
expression, have shown potential roles in the treatment of newly diagnosed myeloid malignancies [7]. Decitabine is firstly approved for the treatment of patients with Myelodysplastic syndrome (MDS) and is also introduced for the treatment of unfit AML patients. Decitabine is already approved in the European Union for AML patients aged $>65$ years who are not eligible for standard induction chemotherapy. Whereas it is not approved in the United States to treat this same group of patients, since a multicenter phase III study was failed statistically to show that elderly AML patients received decitabine lived longer than control group. Multiple clinical trials have been taken to evaluate the treatment advantages of decitabine in elderly AML patients. The purpose of this study was to assess what is currently known about the efficacy and safety of decitabine in elderly AML patients by performing a meta-analysis.

\section{MATERIALS AND METHODS}

\section{Evidence identification}

We performed a comprehensive search of relevant published studies from databases including PubMed, Web of Science, Embase and Cochrane Library. Additional literatures were further investigated through manual search from relevant reference lists to identify any relevant trials. The search strategy was based on the following combined MeSH terms: ("decitabine" or "5-aza-2'-deoxycytidine" or "dacogen") and ("acute myeloid leukemia" or "AML") and ("older" or "elderly"). Restrictions were made on publication language (English only) and population (AML patients aged over 60 years). The publication year was not restricted, and final update of the search was conducted on February 2017.

\section{Study selection and data extraction}

Publications were eligible for this meta-analysis if they met the following inclusion criteria: (1) original research investigated decitabine in treatment of elderly AML; (2) elderly patients aged $\geq 60$ years and met the diagnostic criteria for AML; (3) decitabine used as monotherapy in previously untreated elderly AML patients; (4) provided sufficient information on at least one of the following survival outcomes: $\mathrm{CR}$, overall response rate (ORR) and overall survival (OS); (5) studies are clinical trial, and at least 10 or more patients included in the trial. To minimize bias in the selected literatures, two reviewers independently checked each full-text paper for eligibility according to the same inclusion criteria. Any disagreements were further discussed and resolved by consensus or third party arbitration. General information extracted from eligible studies including first author's name, year of publication, country of origin, trial design, and exact number of patients. The efficacy endpoints of interest were survival outcomes, including CR, ORR and OS. The safety endpoints were treatment related grades 3-4 adverse events (AEs) and early death (ED) rate.

\section{Definition of outcomes and risk of bias in individual studies}

Outcomes were defined according to the 2003 revised International Working Group response criteria [8]. CR was defined by the presence of the following: with < $5 \%$ blasts in bone marrow, with $>1.0 \times 10^{9} / \mathrm{L}$ neutrophils and $>100 \times 10^{9} / \mathrm{L}$ platelet in peripheral blood, and without evidence of extramedullary leukemia. ORR was composed of complete remission, complete remission with incomplete leukocyte or platelet recovery (CRi) and partial response. OS was measured from the date of entry onto a study until death from any cause or was censored at the last follow-up. Each included study was individually assessed risk of bias according to The Cochrane Collaboration's Risk of Bias Assessment Tool following characteristics: sequence generation, allocation concealment, blinding of participants, incomplete outcome data, selective outcome reporting, other sources of bias [9].

\section{Statistical analysis}

The presence of heterogeneity was quantified using the $I^{2}$ statistic, which calculates values between 0 and $100 \%$. Higher value indicates a greater degree of heterogeneity. As a cut-off $P>0.05$ or $I^{2}<50 \%$, fixedeffects model was applied. Otherwise, random-effects model was applied. Estimated proportions (ES) with 95\% confidence intervals (CIs) were calculated for ratio outcomes. Dichotomous variables were pooled by odds ratio (OR) as an effective measurement. Considering some significant prognosis factors, subgroup analyses for response rate were performed based on age, cytogenetics risk, AML type and bone marrow blast if relevant data were available. Funnel plots were inappropriate to present as the total number of included studies were $9(<10)$. Sensitivity analyses were performed by deletion of each single study to evaluate stability of the results. We conducted all the statistical analyses by using Stata software, version 12.0 (Stata Corp, College Station, TX, USA).

\section{RESULTS}

\section{Study characteristics}

A total of 1,358 citations were identified using the initial search strategy, and detailed selection process was illustrated in Figure 1. The yielded 9 studies including 718 patients ultimately qualified for our inclusion criteria in this meta-analysis [10-18]. Characteristics of included studies were summarized in Table 1. Publication years of these studies were ranged from 2010 to 2016. Decitabine treatment 
Table 1: General characteristics of the included studies

\begin{tabular}{|c|c|c|c|c|c|c|}
\hline First Author & Year & Country & Study-center & Phase & $\begin{array}{c}\text { Dose and schedule } \\
\text { of decitabine }\end{array}$ & Trial Sponsor \\
\hline Jacob et al. [10] & 2015 & India & NR & NR & $20 \mathrm{mg} / \mathrm{m}^{2} 5$-days 4 weeks & NR \\
\hline Yan et al. [11] & 2012 & America & Single-center & Phase II & $20 \mathrm{mg} / \mathrm{m}^{2} 10$-days 4 weeks & National Cancer Institute \\
\hline Ritchie et al. [12] & 2013 & America & Single-center & NR & $20 \mathrm{mg} / \mathrm{m}^{2} 10$-days 4 weeks & Leukemia Fighters $^{\mathrm{TM}}$ \\
\hline Cashen et al. [13] & 2010 & America & Multicenter & Phase II & $20 \mathrm{mg} / \mathrm{m}^{2} 5$-days 4 weeks & NR \\
\hline Blum et al. [14] & 2010 & America & Single-center & Phase II & $20 \mathrm{mg} / \mathrm{m}^{2} 10$-days 4 weeks & National Cancer Institute \\
\hline Tawfik et al. [15] & 2014 & America & Single-center & NR & $20 \mathrm{mg} / \mathrm{m}^{2} 5$-days 4 weeks & National Cancer Institute \\
\hline Kantarjian et al. [16] & 2012 & America & Multicenter & Phase III & $20 \mathrm{mg} / \mathrm{m}^{2} 5$-days 4 weeks & MDACC and others \\
\hline Lübbert et al. [17] & 2011 & Germany & Multicenter & Phase II & $15 \mathrm{mg} / \mathrm{m}^{2} 3$-days 6 weeks ${ }^{*}$ & European LeukemiaNet \\
\hline Park et al. [18] & 2016 & Korea & Single-center & NR & $20 \mathrm{mg} / \mathrm{m}^{2} 5$-days 4 weeks & Yonsei University \\
\hline
\end{tabular}

Abbreviations: NR: Not Reached; $15 \mathrm{mg} / \mathrm{m}^{2} 3$-days 6 weeks*: $15 \mathrm{mg} / \mathrm{m}^{2}$, three times daily on 3 consecutive days. MDACC: M.D. Anderson Cancer Center.

schedule varied in the 9 trials. Outcomes of efficacy and safety endpoints in the included patients were presented in Table 2. Baseline characteristics of eligible patients including age, gender, AML type, cytogenetics risk and bone marrow blast were described in Supplementary Table 1.

\section{Efficacy}

Eligible studies were pooled into one dataset for meta-analysis, random-effects models were used to calculate response rates and survival. $\mathrm{CR}$ rates were assessed in eight articles [11-18]. Pooled estimate for overall CR rate was 27\% (95\% CI 19\%-36\%, Figure 2A).
In subgroup analysis of therapy schedule, data from 3-days 6 weeks course showed that CR rate was $13 \%$ (95\% CI 9\%-18\%), and the 5-days 4 weeks course showed a CR rate of $17 \%(95 \%$ CI $13 \%-21 \%)$. The patients treated with 10-days 4 weeks course achieved a significantly higher CR rate of $45 \%(95 \%$ CI $37 \%-54 \%)$ than the other two courses $(P<0.001)$.

ORR was evaluated in eight studies [11-18]. Pooled estimate for ORR of decitabine treated patients was $37 \%$ (95\% CI 28\%-47\%, Figure 2B). Subgroup analysis of ORR with 3-days 6 weeks course was $26 \%(95 \%$ CI 20\%-32\%) and 5-days 4 weeks course was 29\% (95\% CI $22 \%-37 \%$ ). Patients treated with the 10 -days 4 weeks

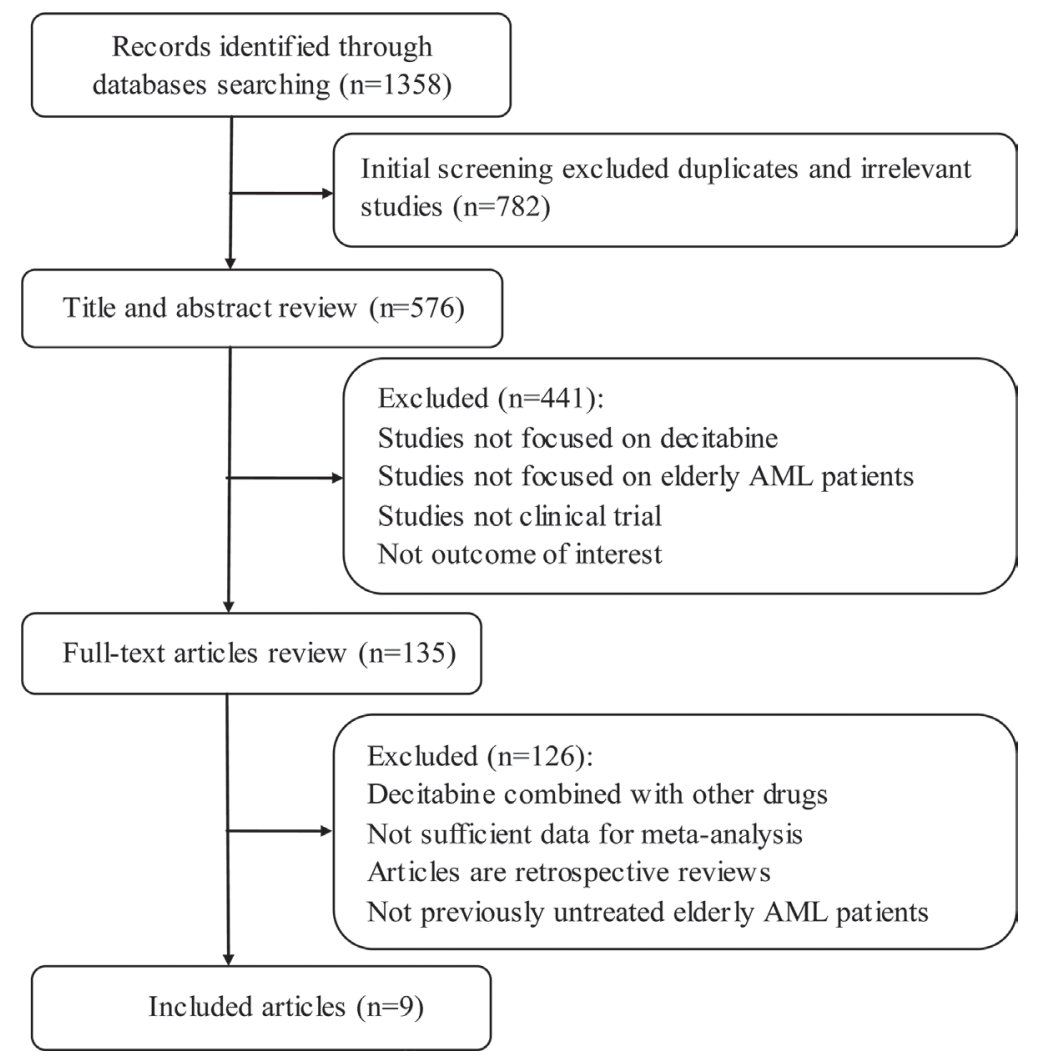

Figure 1: Flow diagram of the included studies selection. AML, Acute myeloid leukemia. 
Table 2: Outcomes of efficacy and safety endpoints in the included patients

\begin{tabular}{lcccccccc}
\hline \multicolumn{1}{c}{ First Author } & $\begin{array}{c}\text { No. } \\
\text { patients }\end{array}$ & $\begin{array}{c}\text { Median age } \\
\text { (years) }\end{array}$ & $\begin{array}{c}\text { Gender } \\
\text { (male\%) }\end{array}$ & $\begin{array}{c}\text { CR } \\
\text { rate }\end{array}$ & ORR & $\begin{array}{c}\text { OS (month ) } \\
\text { range }\end{array}$ & \multicolumn{2}{c}{ ED rate } \\
\hline Jacob et al. [10] & 15 & 65 & 80 & NA & NA & $5.5(1.5-13)$ & 0.067 & 0.067 \\
Yan et al. [11] & 16 & 75 & 50 & 0.563 & 0.563 & NA & NA & NA \\
Ritchie et al. [12] & 52 & 75 & 44 & 0.404 & 0.404 & $10.3(8.8-11.6)$ & 0.058 & 0.154 \\
Cashen et al. [13] & 55 & 74 & 51 & 0.240 & 0.250 & $7.7(5.7-11.6)$ & NA & NA \\
Blum et al. [14] & 53 & 74 & 64 & 0.470 & 0.640 & $13.7(9-18)$ & 0.02 & 0.15 \\
Tawfik et al. [15] & 34 & 75 & 50 & 0.180 & 0.265 & $3.4(1.3-7.4)$ & 0.15 & 0.38 \\
Kantarjian et al. [16] & 242 & 73 & 57 & 0.157 & 0.277 & $7.7(6.2-9.2)$ & 0.09 & 0.197 \\
Lübbert et al. [17] & 227 & 72 & 61 & 0.132 & 0.260 & NA & NA & 0.128 \\
Park et al. [18] & 24 & 73 & 50 & 0.250 & 0.500 & NA & NA & NA \\
\hline A & & 73 &
\end{tabular}

Abbreviations: No.: Number; NA: Not Available; CR: complete remission; ORR: overall response rate; OS: overall survival; ED: early death.

course showed a relatively higher ORR of $53 \%(95 \%$ CI 37\%-70\%). In the different treatment schedule, ORR presented a consistent pattern with CR, 10-days 4 weeks course showed significantly better response than the other two courses $(P=0.001)$.
The OS of elderly AML patients treated with decitabine was analysed in six articles [10,12-16]. Pooled estimate of OS was 8.09 months (95\% CI 5.77-10.41, Figure 2C). In subgroup analysis of therapy schedule, OS of 5-days 4 weeks course was 6.40 months $(95 \% \mathrm{CI}$
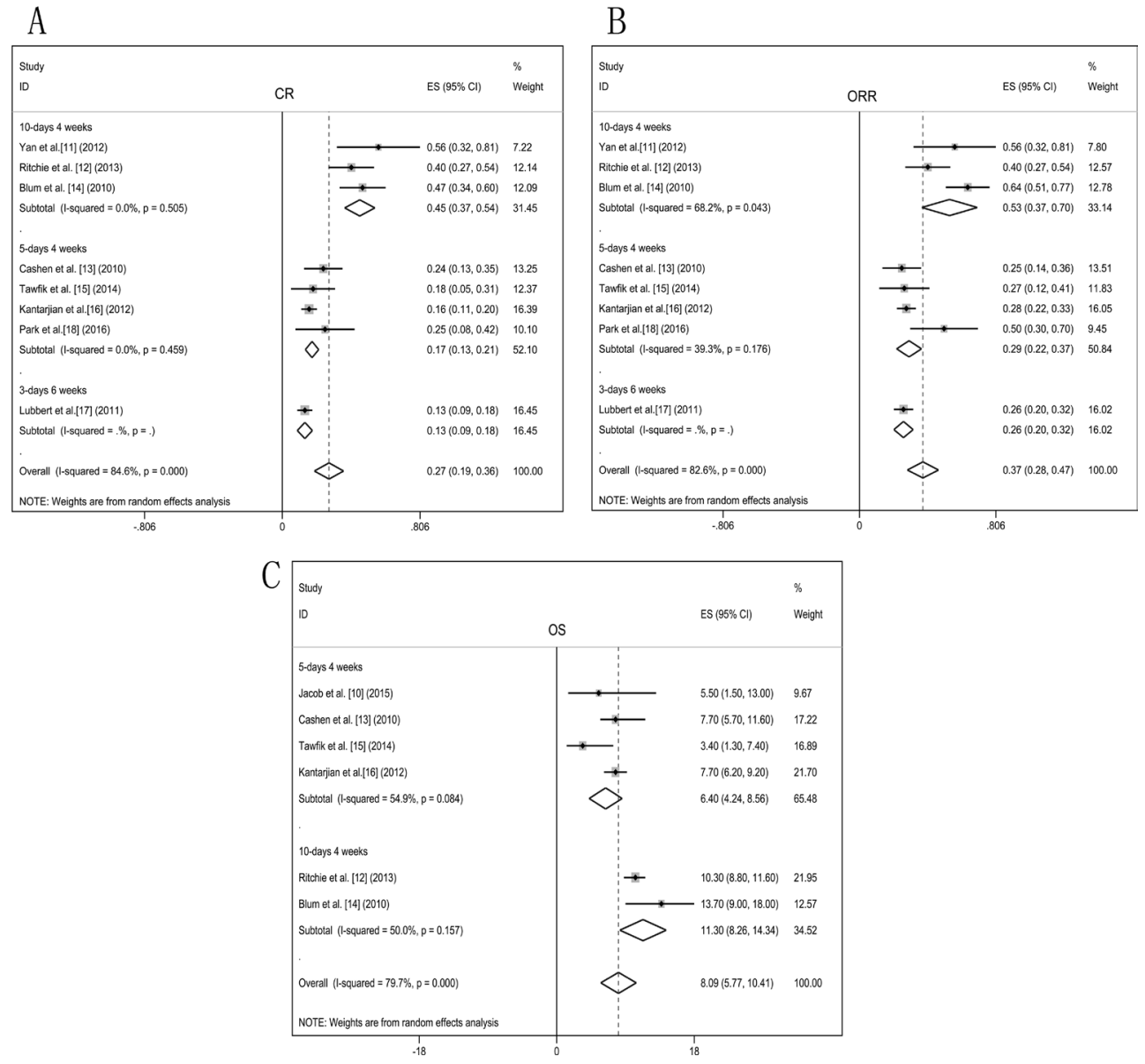

Figure 2: Forest plots of efficacy endpoints of the decitabine treated elderly AML patients. Pooled estimated proportions ( $95 \%$ confidence interval) were generated with random effects models and the respective forest plots are reported: (A) complete remission (CR); (B) overall response rate (ORR); (C) overall survival (OS). 
4.24-8.56) and 10-days 4 weeks course was 11.30 months (95\% CI 8.26-14.34). Subgroup analysis showed that 10-days 4 weeks course achieved a relatively prolonged survival.

\section{Safety}

Regarding toxicity of decitabine, seven studies appraised treatment related grades 3-4 AEs [10, 12-14, 16-18], random-effects model was applied. Myelosuppression was the most common toxicity observed in decitabine treated patients. The reported high risks of treatment related AEs were presented in Figure 3: thrombocytopenia 40\% (95\% CI 28\%$53 \%$ ), febrile neutropenia 38\% (95\% CI 23\%-53\%), neutropenia 37\% (95\% CI 22\%-51\%), anemia 36\% (95\% CI 23\%-48\%) and fatigue 15\% (95\% CI 4\%$26 \%$ ). Occurrence of treatment associated infections was $36 \%$ (95\% CI 24\%-48\%), pneumonia (25\%) and sepsis $(9 \%)$ were the most frequent infectious complications.

Decitabine treatment related ED rates were analysed in six studies [10, 12, 14-17], random-effects model were adopted. Death within 30-days was 7\% (95\% CI 2\%-11\%) and 60-days mortality was 17\% (95\% CI 11\%-22\%, Figure 4A). Subgroup analysis of the association between ED rate and decitabine course with 5-days and 10-days was $31 \%$ (95\% CI 13\%-49\%) and 19\% (95\% CI 11\%-26\%), respectively (Figure 4B). ED rates analyses showed that there was no significant difference in mortality between 5-days and 10-days courses treatment $(P=0.072)$.

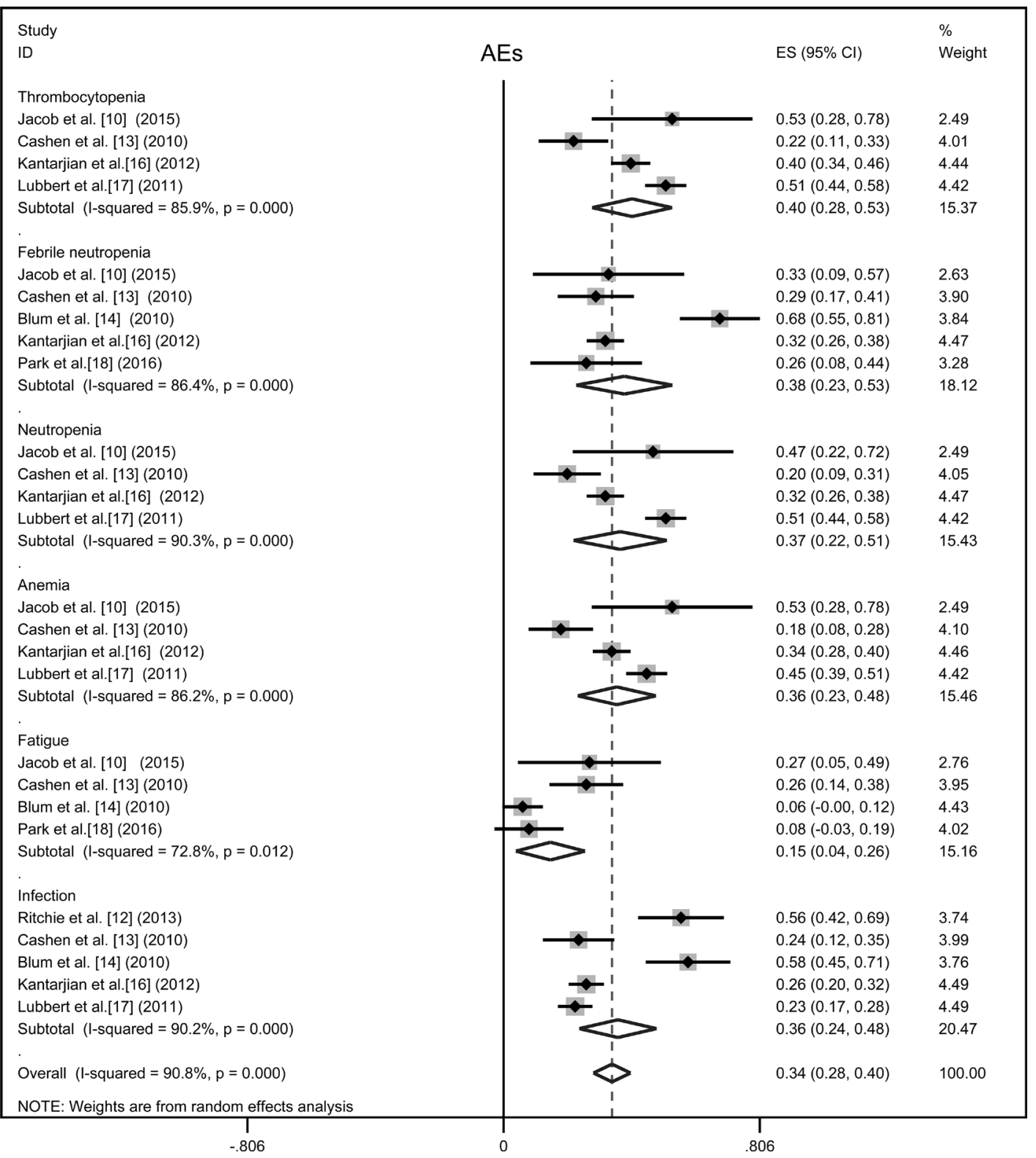

Figure 3: Forest plot of the estimated proportions of most frequent grade 3-4 adverse events (AEs). Pooled estimated proportions (95\% confidence interval) were generated with random effects model. 


\section{Subgroup analyses}

Subgroup analyses of age, cytogenetics risk, AML type and bone marrow blast percentage of response to

A

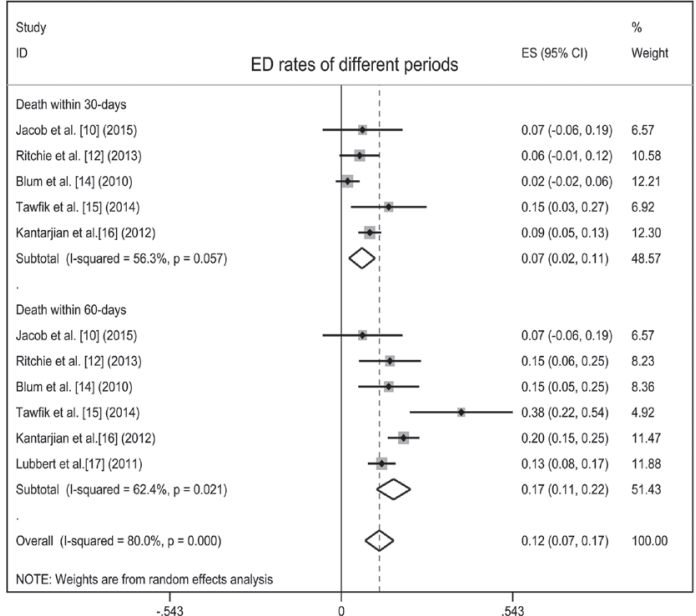

decitabine were performed (Figure 5). A slightly higher proportion of patients with more advanced age $(\geq 70$ years), odds ratio of patients aged $<70$ versus those aged $\geq 70$ was $1.09(95 \%$ CI $0.71-1.68, P=0.691)$, the B

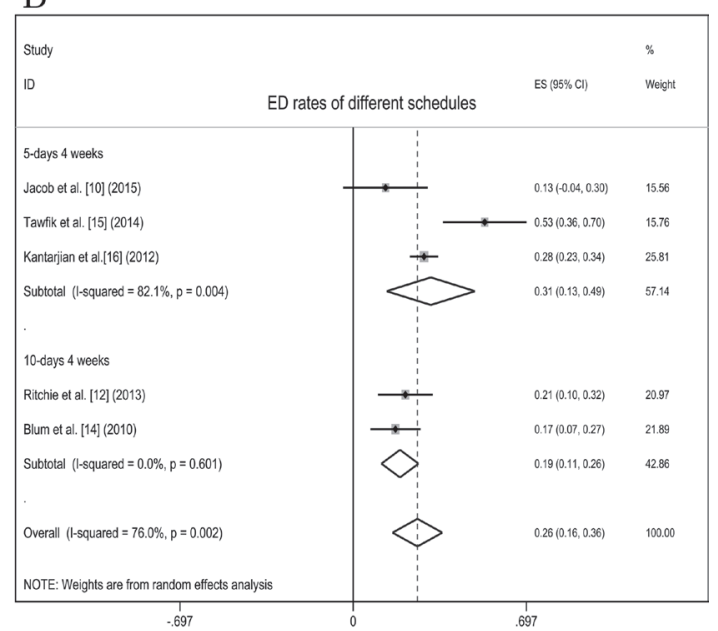

Figure 4: Forest plots of ED rates in elderly AML patients treated with decitabine. Pooled estimated proportions (95\% confidence interval) were generated with random effects models: (A) ED rates of different periods; (B) ED rates of different decitabine schedules.
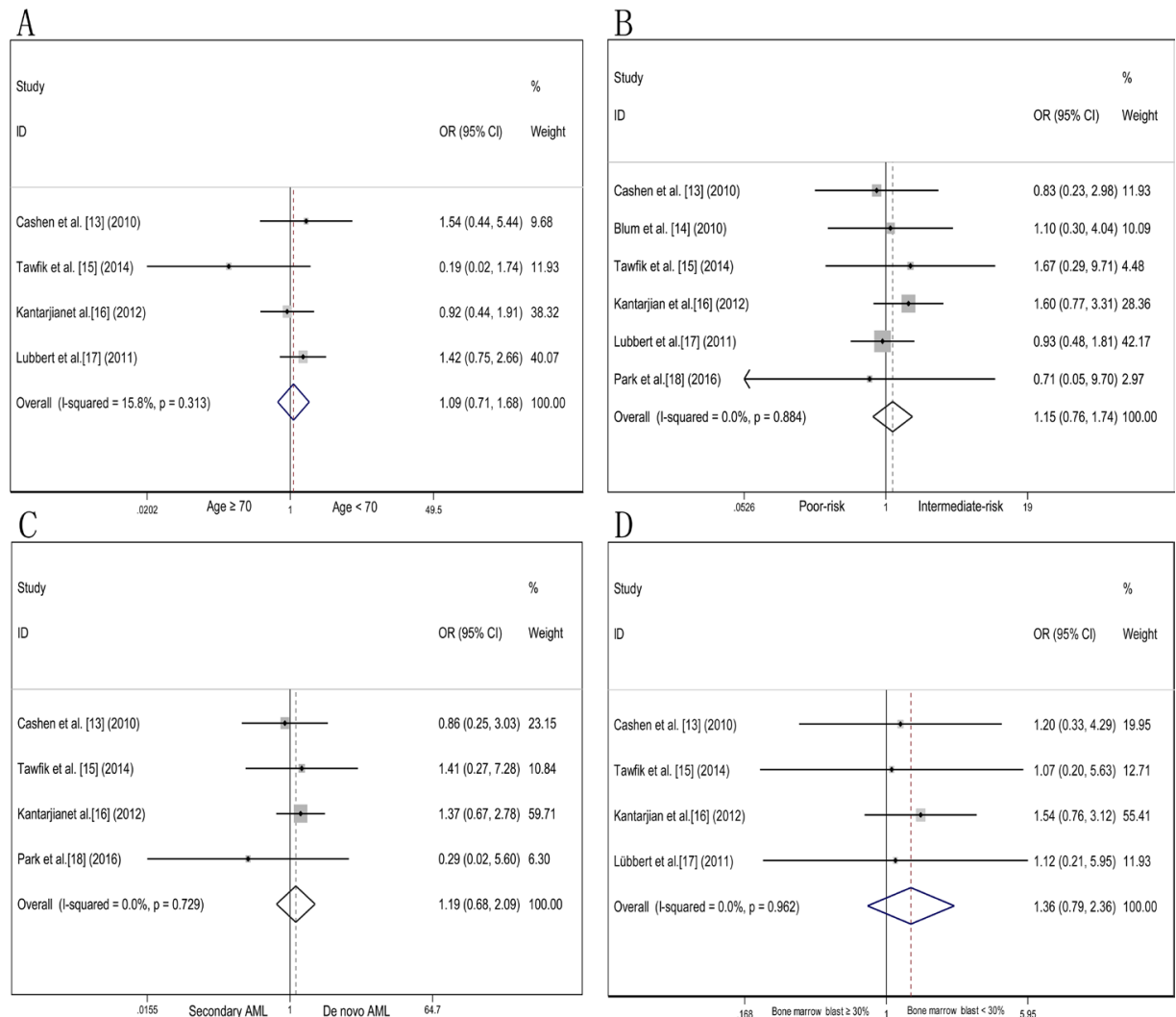

Figure 5: Odds ratio of decitabine response in AML patients according to age, cytogenetics risk, AML type and bone marrow blast percentage. (A) Odds ratio of decitabine treatment response in elderly AML patients aged $<70$ years and $\geq 70$ years. (B) Odds ratio of decitabine treatment response in elderly AML patients cytogenetically profiled with intermediate-risk and poor-risk. (C) Odds ratio of decitabine treatment response in elderly patients diagnosed with de novo AML and secondary AML. (D) Odds ratio of decitabine treatment response in elderly AML patients with bone marrow blast $<30 \%$ and bone marrow blast $\geq 30 \%$. 
two age groups showed equivalent effect to decitabine. Sub-analysis of cytogenetics risk, response odds ratio of intermediate-risk versus poor-risk was $1.15(95 \%$ CI $0.76-1.74, P=0.497)$, favorable-risk was not available to evaluate because of insufficient data. Treatment response of patients diagnosed with de novo AML compared secondary AML, odds ratio was 1.19 (95\% CI $0.68-2.09, P=0.552$ ), suggesting that decitabine have similar effects to the two AML type. Odds ratio of patients with bone marrow blast $<30 \%$ and bone marrow blast $\geq$ $30 \%$ was $1.36(95 \%$ CI $0.97-2.36, P=0.266)$, decitabine treatment response did not show significant difference in patient with discrepant bone marrow blast percentage .

\section{Risk of bias within studies and sensitivity analyses}

Based on the risk of bias assessment criteria, included 9 studies were classified into class B. Detailed assessment information was summarized in Supplementary Table 2. Sensitivity analyses indicated that excluding any single study did not significantly affect the pooled outcomes, suggesting the results of our metaanalysis were stable.

\section{DISCUSSION}

Elderly AML patients are generally less capable of tolerating intensive cytotoxic induction and post-remission chemotherapy. The development of hypomethylating agents provides an alternative treatment strategy [19-28]. This meta-analysis showed that decitabine brought considerable treatment response in elderly AML patients. Preliminary data indicated longer exposure times to decitabine showed an improved response rate and relatively prolonged survival. The dose schedule of decitabine did not seem to affect ED rate with patients receiving 10-days decitabine (19\%) compared with those received 5-days course (31\%). Neutropenia and thrombocytopenia related to myelosuppression were common during decitabine treatment. Prospective clinical trials that directly compared decitabine courses are still needed to confirm the more optimal administration.

Age and cytogenetics risk are important prognostic impact factors of AML patients, this meta-analysis suggests that decitabine can overcome the negative prognostic factors such as advanced age, unfavorable cytogenetic features and even bone marrow blasts $\geq 30 \%$. In addition, chemotherapy outcomes for secondary AML are generally dismal, but decitabine can present comparable effect of de novo AML and secondary AML. Another important factor affecting the prognosis of patients is gene mutations, controversy still exists on predictive value of genetic characteristics (DNA methylation changes and mutations in DNMT3A, TET2, IDH1, IDH2, ASXL1 and expression of miR-29b) to guide decitabine therapy in previous studies $[11,14$,
29-33]. Recently, Welch reported that all patients with TP53 mutation had a response to 10-day courses of decitabine, and $67 \%$ of patients with unfavorable-risk cytogenetic responded to decitabine treatment, survival rate among patients with unfavorable-risk were similar to those with intermediate-risk [34]. TP53 mutations tend to be occurred in older patients with AML, whereas TP53 mutations are usually associated with poor prognosis and low response to standard cytotoxic therapy [35-36]. Welch's trial suggested that decitabine could induce favourable clinical response in patients with AML who have TP53 mutations and who have unfavorable cytogenetic profile.

Decitabine demonstrated activity alone and with combination in elderly AML patients [37-45]. A multicenter, randomized phase III trial indicated that decitabine achieved a higher response rate and a trend toward improved OS compared with low-dose cytarabine or supportive care (7.7 months vs 5.0 months, respectively. $P=0.108)$ in AML patients aged $\geq 65$ years [16]. Decitabine also showed considerable effect compared with intensive chemotherapy in two retrospective studies [21-22]. Gupta N et al and Quintás CA et al reported that intensive chemotherapy could lead higher response rates but no statistically significant differences in OS compared with decitabine induction in older AML patients, and treatment-related ED rate was not statistically different in the two groups. These studies again suggest the potential role of decitabine in elderly patients with AML who cannot tolerate intensive chemotherapy. A phase II, open label trial from China reported an encouraging result in elderly AML patients treated with decitabine in combination with cytarabine, aclarubicin, and granulocyte-colony stimulating factor (decitabine-CAG) [45]. DecitabineCAG combination regimen showed favorable response rates (CR 64.7\% and ORR 82.4\%) and low treatmentrelated adverse effects (induction mortality 4.4\%). A significantly longer median OS in patients with response (16 months) was observed. This study suggests that development of more effective strategies is imperative.

Limitations of our analysis should be considered when interpreting the outcomes. First, despite the same inclusion criteria, significant heterogeneity was detected. Second, sample size of subgroup analyses was relatively small. Third, we didn't explore gene mutation and treatment response interactions because of the insufficient data. Finally, considering a higher quality and credibility of eligible studies, only published studies were included. Confounding cannot be avoided and should be considered in this meta-analysis. Despite these limitations, our review is the first comprehensive meta-analysis of all eligible studies on the efficacy and safety of decitabine treated elderly AML patients.

In conclusion, our meta-analysis suggests that decitabine is an effective and well-tolerated therapeutic alternative with acceptable side effects in elderly AML patients. To improve the overall response and 
maintain durable remission, further studies should focus on determining the best administration schedule and developing the optimal combination with decitabine.

\section{Abbreviations}

AML: acute myeloid leukemia; 95\% CI: confidence interval; CR: complete remission; ORR: overall response rate; OS: overall survival; ED: early death; AEs: adverse events; OR: odds ratio.

\section{Authors' contributions}

Conceptualization: Pin-fang He, Jiang Lin. Data curation: Pin-fang He, Jiang Lin. Formal analysis: Pinfang He, Dong-ming Yao. Funding acquisition: Jun Qian. Investigation: Xiang-mei Weng, Pin-fang He. Methodology: Pin-fang He, Jing-dong Zhou, Dongming Yao. Project administration: Jiang Lin, Jun Qian. Resources: Ji-chun Ma, Zhi-hui Zhang, Zi-jun Xu. Software: Pin-fang He, Xin-yue Lian. Supervision: Jiang Lin, Jun Qian. Validation: Jing-dong Zhou, Dong-ming Yao. Visualization: Jing-dong Zhou, Ji-chun Ma. Writing - original draft: Pin-fang He. Writing - review\& editing: Pin-fang He, Jiang Lin, Jun Qian.

\section{ACKNOWLEDGMENTS}

This work was supported by the National Natural Science Foundation of China (81270630), Special Funds of "Ke Jiao Qiang Wei” Project of Jiangsu Province, 333 Project of Jiangsu Province (BRA2016131), Six Talent Peaks Project of Jiangsu Province (2015-WSN-115), China Postdoctoral Science Foundation funded project (2016M601748), Social Development Foundation of Zhenjiang (SH2015058, SH2016045, SH2016046), Social Development Foundation of Kunshan (KS1624), and Key Medical Talent Program of Zhenjiang City.

\section{CONFLICTS OF INTEREST}

The authors declare that they have no conflicts of interest.

\section{REFERENCES}

1. Bravo GM, Garcia-Manero G. Novel drugs for older patients with acute myeloid leukemia. Leukemia. 2015; 29:760-9.

2. Thomas XG, Arthur C, Delaunay J, Jones M, Berrak E, Kantarjian HM. A post hoc sensitivity analysis of survival probabilities in a multinational phase III trial of decitabine in older patients with newly diagnosed acute myeloid leukemia. Clin Lymphoma Myeloma Leuk. 2014; 14:68-72.
3. Grishina O, Schmoor C, Döhner K, Hackanson B, Lubrich B, May AM, Cieslik C, Müller MJ, Lübbert M. DECIDER: prospective randomized multicenter phase II trial of low-dose decitabine (DAC) administered alone or in combination with the histone deacetylase inhibitor valproic acid (VPA) and all-trans retinoic acid (ATRA) in patients > 60 years with acute myeloid leukemia who are ineligible for induction chemotherapy. BMC Cancer. 2015; 15:430.

4. Kadia TM, Faderl S, Ravandi F, Ravandi F, Jabbour E, Garcia-Manero G, Borthakur G, Ferrajoli A, Konopleva M, Burger J, Huang XL, Wang XM, Pierce S, et al. Final results of a phase 2 trial of clofarabine and low-dose cytarabine alternating with decitabine in older patients with newly diagnosed acute myeloid leukemia. Cancer. 2015; 121:2375-82.

5. Wang ES. Treating acute myeloid leukemia in older adults. Hematology Am Soc Hematol Educ Program. 2014; 2014:14-20.

6. Erba HP. Finding the optimal combination therapy for the treatment of newly diagnosed AML in older patients unfit for intensive therapy. Leuk Res. 2015; 39:183-91.

7. Curran MP. Decitabine: a review of its use in older patients with acute myeloid leukaemia. Drugs Aging. 2013; 30: 447-58.

8. Cheson BD, Bennett JM, Kopecky KJ, Büchner T, Willman CL, Estey EH, Schiffer CA, Doehner H, Tallman MS, Lister TA, Lo-Coco F, Willemze R, Biondi A, et al. Revised recommendations of the International Working Group for Diagnosis, Standardization of Response Criteria, Treatment Outcomes, and Reporting Standards for Therapeutic Trials in Acute Myeloid Leukemia. J Clin Oncol. 2003; 21:4642-9.

9. Higgins JP, Altman DG, Gøtzsche PC, Jüni P, Moher D, Oxman AD, Savovic J, Schulz KF, Weeks L, Sterne JA, Cochrane Bias Methods Group, Cochrane Statistical Methods Group. The Cochrane Collaboration's tool for assessing risk of bias in randomised trials. BMJ. 2011; 343:d5928.

10. Jacob LA, Aparna S, Lakshmaiah KC, Lokanatha D, Babu G, Babu S, Appachu S. Decitabine Compared with Low-Dose Cytarabine for the Treatment of Older Patients with Newly Diagnosed Acute Myeloid Leukemia: A Pilot Study of Safety, Efficacy, and Cost-Effectiveness. Adv Hematol. 2015; 2015:167029.

11. Yan P, Frankhouser D, Murphy M, Tam HH, Rodriguez B, Curfman J, Trimarchi M, Geyer S, Wu YZ, Whitman SP, Metzeler K, Walker A, Klisovic R, et al. Genome-wide methylation profiling in decitabine-treated patients with acute myeloid leukemia. Blood. 2012; 120:2466-74.

12. Ritchie EK, Feldman EJ, Christos PJ, Rohan SD, Lagassa CB, Ippoliti C, Scandura JM, Carlson K, Roboz GJ. Decitabine in patients with newly diagnosed and relapsed acute myeloid leukemia. Leuk Lymphoma. 2013; 54:2003-7. 
13. Cashen AF, Schiller GJ, O'Donnell MR, DiPersio JF. Multicenter, phase II study of decitabine for the first-line treatment of older patients with acute myeloid leukemia. J Clin Oncol. 2010;28:556-61.

14. Blum W, Garzon R, Klisovic RB, Schwind S, Walker A, Geyer S, Liu SJ, Havelange V, Becker H, Schaaf L, Mickle J, Devine H, Kefauver C, et al. Clinical response and miR-29b predictive significance in older AML patients treated with a 10-day schedule of decitabine. Proc Natl Acad Sci USA. 2010;107:7473-8.

15. Tawfik B, Sliesoraitis S, Lyerly S, Klepin HD, Lawrence J, Isom S, Ellis LR, Manuel M, Dralle S, Berenzon D, Powell BL, Pardee T. Efficacy of the hypomethylating agents as frontline, salvage, or consolidation therapy in adults with acute myeloid leukemia (AML). Ann Hematol. 2014; 93:47-55.

16. Kantarjian H, Thomas XG, Dmoszynska A, Wierzbowska A, Mazur G, Mayer J, Gau JP, Chou WC, Buckstein R, Cermak J, Kuo CY, Oriol A, Ravandi F, et al. Multicenter, randomized, open-label, phase III trial of decitabine versus patient choice, with physician advice, of either supportive care or low-dose cytarabine for the treatment of older patients with newly diagnosed acute myeloid leukemia. J Clin Oncol. 2012; 30:2670-7.

17. Lübbert, Rüter BH, Claus R, Schmoor C, Schmid M, Germing U, Kuendgen A, Rethwisch V, Ganser A, Platzbecker U, Galm O, Brugger W, Heil G, et al. A multicenter phase II trial of decitabine as first-line treatment for older patients with acute myeloid leukemia judged unfit for induction chemotherapy. Haematologica. 2012; 97: 393-401.

18. Park H, Chung H, Lee J, Jang J, Kim Y, Kim SJ, Kim JS, Min YH, Cheong JW. Decitabine as the first-line treatment for elderly patients with acute myeloid leukemia; a single center experience in Korea. Haematologica. 2015; 100:658 658.

19. Blum W, Klisovic RB, Hackanson B, Liu ZF, Liu SJ, Devine H, Vukosavljevic T, Huynh L, Lozanski G, Kefauver C, Plass C, Devine SM, Heerema NA, et al. Phase I study of decitabine alone or in combination with valproic acid in acute myeloid leukemia. J Clin Oncol. 2007; 25:3884-91.

20. Issa JP, Garcia-Manero G, Huang XL, Cortes J, Ravandi F, Jabbour E, Borthakur G, Brandt M, Pierce S, Kantarjian H. Results of Phase II Randomized Study of Low-Dose Decitabine with or without Valproic Acid in Patients with Myelodysplastic Syndrome and Acute Myelogenous Leukemia. Cancer. 2015; 121:556-561.

21. Gupta N, Miller A, Gandhi S, Ford LA, Vigil CE, Griffiths EA, Thompson JE, Wetzler M, Wang ES. Comparison of epigenetic versus standard induction chemotherapy for newly diagnosed acute myeloid leukemia patients $\geq 60$ years old. Am J Hematol. 2015; 90:639-46.
22. Quintás-Cardama A, Ravandi F, Liu-Dumlao T, Brandt M, Faderl S, Pierce S, Borthakur G, Garcia-Manero G, Cortes J, Kantarjian H. Epigenetic therapy is associated with similar survival compared with intensive chemotherapy in older patients with newly diagnosed acute myeloid leukemia. Blood. 2012; 120:4840-5.

23. Srivastava P, Paluch BE, Matsuzaki J, James SR, CollamatLai G, Blagitko-Dorfs N, Ford LA, Naqash R, Lübbert M, Karpf AR, Nemeth MJ, Griffiths EA. Induction of cancer testis antigen expression in circulating acute myeloid leukemia blasts following hypomethylating agent monotherapy. Oncotarget. 2016; 7:12840-56. doi: 10.18632/ oncotarget.7326.

24. He JM, Xiu L, Porre PD, Dass R, Thomas X. Decitabine reduces transfusion dependence in older patients with acute myeloid leukemia: results from a post hoc analysis of a randomized phase III study. Leuk Lymphoma. 2015; 56:1033-42.

25. Baer MR, Gojo I. Novel agents for the treatment of acute myeloid leukemia in the older patient. J Natl Compr Canc Netw. 2011; 9:331-5.

26. Momparler RL, Côté S, Momparler LF. Epigenetic action of decitabine (5-aza-2'-deoxycytidine) is more effective against acute myeloid leukemia than cytotoxic action of cytarabine (ARA-C). Leuk Res. 2013; 37:980-4.

27. Blum W, Schwind S, Tarighat SS, Geyer S, Eisfeld AK, Whitman S, Walker A, Klisovic R, Byrd JC, Santhanam R, Wang H, Curfman JP, Devine SM, et al. Clinical and pharmacodynamic activity of bortezomib and decitabine in acute myeloid leukemia. Blood. 2012;119:6025-31.

28. Bryan J, Kantarjian HM, Garcia-Manero G, Jabbour E. Pharmacokinetic evaluation of decitabine for the treatment of leukemia. Expert Opinion On Drug Metabolism \& Toxicology. 2011; 7:661-672.

29. Dinardo CD, Patel KP, Garcia-Manero G, Luthra R, Pierce S, Borthakur G, Jabbour E, Kadia T, Pemmaraju N, Konopleva M, Faderl S, Cortes J, Kantarjian HM, et al. Lack of association of IDH1, IDH2 and DNMT3A mutations with outcome in older patients with acute myeloid leukemia treated with hypomethylating agents. Leuk Lymphoma. 2014; 55:1925-9.

30. Metzeler KH, Walker A, Geyer S, Garzon R, Klisovic RB, Bloomfield CD, Blum W, Marcucci G. DNMT3A mutations and response to the hypomethylating agent decitabine in acute myeloid leukemia. Leukemia. 2012; 26:1106-7.

31. Metzeler $\mathrm{KH}$, Becker H, Maharry K, Radmacher MD, Kohlschmidt J, Mrózek K, Nicolet D, Whitman SP, Wu YZ, Schwind S, Powell BL, Carter TH, Wetzler M, et al. ASXL1 mutations identify a high-risk subgroup of older patients with primary cytogenetically normal AML within the ELN Favorable genetic category. Blood. 2011; 118:6920-9.

32. Metzeler KH, Maharry K, Radmacher MD, Mrózek K, Margeson D, Becker H, Curfman J, Holland KB, Schwind S, Whitman SP, Wu YZ, Blum W, Powell BL, et al. 
TET2 mutations improve the new European LeukemiaNet risk classification of acute myeloid leukemia: a Cancer and Leukemia Group B study. J Clin Oncol. 2011; 29:1373-81.

33. Ohgami RS, Ma L, Merker JD, Gotlib JR, Schrijver I, Zehnder JL, Arber DA. Next-generation sequencing of acute myeloid leukemia identifies the significance of TP53, U2AF1, ASXL1, and TET2 mutations. Mod Pathol. 2015; 28:706-14.

34. Welch JS, Petti AA, Miller CA, Fronick CC, O'Laughlin M, Fulton RS, Wilson RK, Baty JD, Duncavage EJ, Tandon B, Lee YS, Wartman LD, Uy GL, et al. TP53 and Decitabine in Acute Myeloid Leukemia and Myelodysplastic Syndromes. N Engl J Med. 2016; 375:2023-2036.

35. Rücker FG, Schlenk RF, Bullinger L, Kayser S, Teleanu V, Kett H, Habdank M, Kugler Carla-M, Holzmann K, Gaidzik VI, Paschka P, Held G, von Lilienfeld-Toal M, et al. TP53 alterations in acute myeloid leukemia with complex karyotype correlate with specific copy number alterations, monosomal karyotype, and dismal outcome. Blood. 2012; 119:2114-21.

36. Hou HA, Chou WC, Kuo YY, Liu CY, Lin LI, Tseng MH, Chiang YC, Liu MC, Liu CW, Tang JL, Yao M, Li CC, Huang SY, et al. TP53 mutations in de novo acute myeloid leukemia patients: longitudinal follow-ups show the mutation is stable during disease evolution. Blood Cancer J. 2015; 5:e331.

37. Scandura JM, Roboz GJ, Moh M, Morawa E, Brenet F, Bose R, Villegas L, Gergis US, Mayer SA, Ippoliti CM, Curcio TJ, Ritchie EK, Feldman EJ. Phase 1 study of epigenetic priming with decitabine prior to standard induction chemotherapy for patients with AML. Blood. 2011; 118:1472-80.

38. Lin J, Zhu HL, Li SX, Fan H, Lu XC, Chang C, Guo B, Zhai B. Successful treatment with low-dose decitabine in acute myelogenous leukemia in elderly patients over 80 years old: Five case reports. Oncology Letters. 2013; 5:1321-1324.
39. Malik P, Cashen AF. Decitabine in the treatment of acute myeloid leukemia in elderly patients. Cancer Manag Res. 2014; 6:53-61.

40. Lübbert $M$, Bertz H, Rüter B, Marks R, Claus R, Finke J. Non-intensive treatment with low-dose 5-aza-2'deoxycytidine (DAC) prior to allogeneic blood SCT of older MDS/AML patients. Bone Marrow Transplantation. 2009; 44:585-588.

41. Jiang XJ, Wang ZX, Ding BJ, Yin CX, Zhong QX, Carter BZ, Yu G, Jiang L, Ye JY, Dai M, Zhang Y, Liang S, Zhao QX, et al. The hypomethylating agent decitabine prior to chemotherapy improves the therapy efficacy in refractory/ relapsed acute myeloid leukemia patients. Oncotarget. 2015; 6:33612-22. doi: 10.18632/oncotarget.5600.

42. Jing Y, Jin X, Wang L, Dou L, Wang Q, Yao Y, Lian S, Zhou J, Zhu H, Yao Z, Gao L, Wang L, Li Y, et al. Decitabine-based chemotherapy followed by haploidentical lymphocyte infusion improves the effectiveness in elderly patients with acute myeloid leukemia. Oncotarget. 2016 Aug 10. doi: 10.18632/oncotarget.11183. [Epub ahead of print].

43. Al-Ali H, Jaekel N, Niederwieser D. The role of hypomethylating agents in the treatment of elderly patients with AML. Journal Of Geriatric Oncology. 2014; 5:89-105.

44. Daver N, Kantarjian H, Ravandi F, Estey E, Wang X, Garcia-Manero G, Jabbour E, Konopleva M, O'Brien S, Verstovsek S, Kadia T, Dinardo C, Pierce S, et al. A phase II study of decitabine and gemtuzumab ozogamicin in newly diagnosed and relapsed acute myeloid leukemia and high-risk myelodysplastic syndrome. Leukemia. 2016; 30:268-273.

45. Li JY, Chen YY, Zhu Y, Zhou JF, Xu YL, Li Y, Yu K, Pan L, Wang JM, Ding JH, Gu J, Zhou SH, Qian SX, et al. Efficacy and safety of decitabine in combination with G-CSF, lowdose cytarabine and aclarubicin in newly diagnosed elderly patients with acute myeloid leukemia. Oncotarget. 2015; 6:6448-58. doi: 10.18632/oncotarget.3361. 